\title{
Effects of dasatinib on EphA2 receptor tyrosine kinase activity and downstream signalling in pancreatic cancer
}

\author{
Q Chang', C Jorgensen², T Pawson ${ }^{2,3}$ and DW Hedley, ${ }^{*, 1,4,5}$ \\ 'Division of Applied Molecular Oncology, Ontario Cancer Institute/Princess Margaret Hospital, Toronto, Ontario, Canada M5G 2M9; ${ }^{2}$ Samuel Lunenfeld \\ Research Institute, Mount Sinai Hospital, Toronto, Ontario, Canada M5G IX5; ${ }^{3}$ Department of Molecular and Medical Genetics, University of Toronto, \\ Toronto, Ontario, Canada M5S IA8; ${ }^{4}$ Department of Medical Oncology and Hematology, Ontario Cancer Institute/Princess Margaret Hospital, Toronto, \\ Ontario, Canada M5G 2M9; ${ }^{5}$ Department of Medical Biophysics, University of Toronto, Toronto, Ontario, Canada M5S IA8
}

Eph receptors constitute the largest family of receptor tyrosine kinases in the human genome. EphA2 is one prominent member that is overexpressed and functionally altered in many invasive cancers, including pancreatic cancer. Dasatinib, which is a multi-targeted kinase inhibitor mainly developed for Bcr-Abl and Src family kinases, has recently been shown to have significant activity against EphA2. As selective small molecule EphA2 inhibitors are not currently available, we investigated the therapeutic potential to target EphA2 by dasatinib in pancreatic cancer cell lines. Using in vitro kinase assays, we found that EphA2 receptor tyrosine kinase was inhibited directly by dasatinib in a dose-dependent manner. Stimulation with ephrinAl produced rapid increases of EphA2 phosphorylation that were inhibited by dasatinib, although the effects on activation of downstream signalling differed among the pancreatic cancer cell lines. Dasatinib also inhibited ligand-induced binding of EphA2 to the ubiquitin ligase Cbl, and the internalisation and degradation of EphA2, suggesting that these processes are dependent on kinase activity. Treatment with dasatinib decreased EphA2 phosphorylation in BxPC-3 xenografts, suggesting that dasatinib might have activity in pancreatic cancer due to EphA2 inhibition, besides its effects on Src. British Journal of Cancer (2008) 99, 1074- 1082. doi:I0.1038/sj.bjc.6604676 www.bjcancer.com Published online 16 September 2008

(c) 2008 Cancer Research UK

Keywords: EphA2; receptor tyrosine kinase; pancreatic cancer; dasatinib; xenografts

The Eph family of receptor tyrosine kinases (RTKs), with at least 14 distinct members in mammals, constitutes the largest subfamily of RTKs (Pasquale, 2004). Eph RTKs are divided into two subclasses (EphA and EphB) based on sequence similarity and their preferential binding to ligands, which are tethered to the cell surface either by a glycosylphosphatidylinositol-anchor (ephrinA) or by a single transmembrane domain (Kullander and Klein, 2002). Upon ligand binding, Eph receptors multimerise and become phosphorylated (Dodelet and Pasquale, 2000). Eph RTKs are increasingly understood to have significant functions in disease and development (Zantek et al, 1999). In normal development, Eph receptors frequently control the compartmentalisation of cells in complex tissues such as the vascular system, brain and intestinal epithelium, through their ability to mediate cellular repulsion and adhesion. In tumourigenesis, they have been implicated in cellular transformation, metastasis and angiogenesis (Nakamoto and Bergemann, 2002). For example, B type receptors appear to suppress the invasiveness of colon cancer cells (Batlle et al, 2005), whereas A type receptors such as EphA2 may have a pro-oncogenic effect.

*Correspondence: Dr DW Hedley, Department of Medical Oncology and Hematology, Ontario Cancer Institute/Princess Margaret Hospital, 610, University Avenue, Toronto, Ontario, Canada M5G 2M9;

E-mail: david.hedley@uhn.on.ca

Revised 21 August 2008; accepted 25 August 2008; published online 16 September 2008
EphA2 critically controls many aspects of cell behaviour (Kinch and Carles-Kinch, 2003). Epithelial cells normally form stable linkages with adjacent cells, and express low levels of EphA2 that are enriched within intercellular junctions (Zantek et al, 1999). This localisation favours stable ligand binding, and indeed, EphA2 on normal epithelial cells is autophosphorylated (Zantek et al, 1999; Miao et al, 2001). In contrast, malignant cells generally show unstable cell-cell contacts (Kinch and Burridge, 1995), and a consequence of this change is that the high levels of EphA2 on malignant cells fail to bind ligand and thus become diffusely distributed over the cell surface (Zantek et al, 1999; Macrae et al, 2005). Thus, EphA2 function can be altered in malignant cells (Kinch and Carles-Kinch, 2003). EphA2 is also frequently overexpressed and functionally altered in many invasive cancers (Walker-Daniels et al, 2003). For example, high levels of EphA2 have been documented in metastatic melanoma, as well as cancers of the mammary gland, cervix, ovary, prostate, colon, lung, kidney, esophagus and pancreas (Easty et al, 1995; Ogawa et al, 2000; Zantek et al, 2001; Zelinski et al, 2001; Nakamoto and Bergemann, 2002; Kinch et al, 2003; Miyazaki et al, 2003; Ireton and Chen, 2005; Mudali et al, 2006).

However, despite the strong correlation of EphA2 receptor expression with malignant phenotypes, the mechanisms by which EphA2 contributes to tumour cell malignancy are far from clear (Fang et al, 2005). Some evidence supports the idea that EphA2 receptor phosphorylation is not necessary to confer kinase activity and tumorigenicity (Zantek et al, 1999; Walker-Daniels et al, 2002), or is even tumour suppressive (Guo et al, 2006). Other data 
suggest that EphA2 receptor phosphorylation may be important in conferring the oncogenic potential (Ogawa et al, 2000; Brantley et al, 2002; Dobrzanski et al, 2004). Hence, EphA2 represents a therapeutic target for novel anticancer agents.

Dasatinib is an oral dual Bcr/Abl and Src family kinases inhibitor, approved for use in patients with chronic myelogenous leukaemia and currently tested as an Src inhibitor (Talpaz et al, 2006). In a recent report, Huang et al (Huang et al, 2007) showed that EphA2 was highly expressed in dasatinib-sensitive cell lines and that EphA2 was also inhibited by dasatinib. Furthermore, EphA2 and several other members of Eph RTKs have been shown as targets of dasatinib by gene expression and a chemical proteomic profiling approach (Bantscheff et al, 2007; Rix et al, 2007; Wang et al, 2007). As EphA2 is frequently overexpressed in pancreatic cancer (Duxbury et al, 2004; Mudali et al, 2006), and selective small molecule EphA2 inhibitors are not currently available, we investigated the therapeutic potential to target EphA2 by dasatinib in several pancreatic cancer cell lines as well as in BxPC-3 xenografts.

\section{MATERIALS AND METHODS}

\section{Cell lines}

The human pancreatic cancer cell lines BxPC-3, PANC-1, MIA PaCa-2 and human embryonic kidney (HEK) 293 cell line were obtained from American Type Culture Collection (Manassas, VA, USA). BxPC-3 was grown in RPMI-1640 with $10 \%$ fetal bovine serum (FBS). PANC-1 was grown in Dulbecco's modified Eagle's medium (DMEM)-H21 with $10 \%$ FBS. MIA PaCa-2 was grown in DMEM-H21 with $10 \%$ FBS and $2.5 \%$ horse serum. HEK-293 was grown in DMEM with $10 \%$ FBS. Cells were maintained at $37^{\circ} \mathrm{C}$ under standard cell culture conditions.

\section{Reagents and antibodies}

Mouse monoclonal antibodies against phosphotyrosine (P-Tyr-100), phospho-STAT3 (Tyr705) as well as rabbit polyclonal antibodies against phospho-Src (Tyr416), phospho-FAK (Tyr576/ 577), phospho-FAK (Tyr925), phospho-Akt (Ser473), phosphoPaxillin (Tyr118), phospho-p44/42 MAPK (Thr202/Tyr204) and antibodies directed against their nonphosphorylated counterparts, were purchased from Cell Signaling Technology (Beverly, MA, USA). Mouse monoclonal antibody against phospho-STAT3 (Ser727) was from BD Biosciences (Mississauga, Ontario, Canada). Rabbit polyclonal antibodies directed against EphA2 and $\mathrm{Cbl}$ were obtained from Santa Cruz Biotechnology Inc. (Santa Cruz, CA, USA). A mouse monoclonal antibody against EphA2 and recombinant mouse ephrin-A1/Fc chimera were from $R \& D$ Systems Inc. (Minneapolis, MN, USA). The secondary antibodies for western blots (anti-mouse and anti-rabbit IgG antibodies) were from Amersham Biosciences (Buckinghamshire, United Kingdom). Protein G-Sepharose was from Sigma-Aldrich Canada Ltd. (Oakville, Ontario, Canada). AffiniPure goat anti-human IgG, $\mathrm{Fc}_{\gamma}$ fragment-specific was from Jackson ImmunoResearch laboratories Inc. (West Grove, PA, USA). $\left[\gamma-{ }^{32} \mathrm{P}\right] \mathrm{ATP}$ was from New England Nuclear (Boston, MA, USA).

\section{Drug preparation}

Dasatinib was purchased from Toronto Research Chemicals (North York, Ontario, Canada). PP2 was purchased from Calbiochem (San Diego, CA, USA). Dasatinib and PP2 used for tissue culture were both dissolved in DMSO, aliquoted, and stored at appropriate temperature. Dasatinib was prepared freshly as a $12.5 \mathrm{mg} \mathrm{ml}^{-1}$ suspension in $80 \mathrm{~mm}$ sodium citrate/citric acid buffer, $\mathrm{pH} 3.0$ for oral gavage in vivo.

\section{In vitro kinase assays}

In vitro autophosphorylation assays were essentially performed as described earlier (Holland et al, 1997). HEK-293 cells were transfected with cDNA-encoding human EphA2 or human EphB2. Cells were lyzed $20 \mathrm{~h}$ later and EphA2 or EphB2 was immunoprecipitated. Immunoprecipitated EphA2 or EphB2 was washed in lysis buffer $\left[50 \mathrm{mmoll}^{-1}\right.$ HEPES (pH 7.5), 10\% glycerol, $1 \%$ Triton X-100, $150 \mathrm{mmoll}^{-1} \mathrm{NaCl}$, $1 \mathrm{mmoll}^{-1}$ EGTA, $1.5 \mathrm{mmoll}^{-1} \mathrm{MgCl}_{2}, 100 \mathrm{mmoll}^{-1} \mathrm{NaF}, 10 \mathrm{mmoll}^{-1}$ $\left.\mathrm{Na}_{4} \mathrm{P}_{2} \mathrm{O}_{7} \cdot 10 \mathrm{H}_{2} \mathrm{O}, 1 \mathrm{mmoll}^{-1} \mathrm{Na}_{3} \mathrm{VO}_{4}\right]$ and kinase reaction buffer, incubated with dasatinib $(0,20,100$ and $200 \mathrm{nM}$, final DMSO concentration $0.05 \%$ in all reactions) at room temperature for $10 \mathrm{~min}$ and then incubated with $10 \mu \mathrm{Ci}$ of $\left[\gamma^{32} \mathrm{P}\right] \mathrm{ATP}$ at room temperature for $30 \mathrm{~min}$. The reactions were terminated by the addition of $6 \times$ Laemmli sample buffer and boiling. After resolving samples by $10 \%$ SDS-PAGE, the gel was stained with Coomassie blue to check for equal loading, then dried and exposed.

\section{Cell proliferation assay}

BxPC-3, PANC-1 and MIA PaCa-2 cells were cultured in 96-well plates at 5000 cells per well in $100 \mu \mathrm{l}$ complete medium and then pretreated with $0,25,50,100$ and $200 \mathrm{~nm}$ dasatinib for $48 \mathrm{~h}$. According to the manufacturer's instructions, viable cell number was determined using a colorimetric method based on the cellular reduction of the tetrazolium compound 3-(4,5-dimethylthiazol-2yl)-5-(3-carboxymethoxyphenyl)-2-(4-sulfophenyl)-2H-tetrazolium (MTS) into a soluble coloured formazan product (CellTiter 96 Aqueous One Solution Cell Proliferation Assay, Promega Corp., Madison, WI, USA).

\section{Cell cycle analysis}

Subconfluent BxPC-3, PANC-1 and MIA PaCa-2 cells were treated with $0,25,50,100$ and $200 \mathrm{~nm}$ dasatinib for $24 \mathrm{~h}$, and then

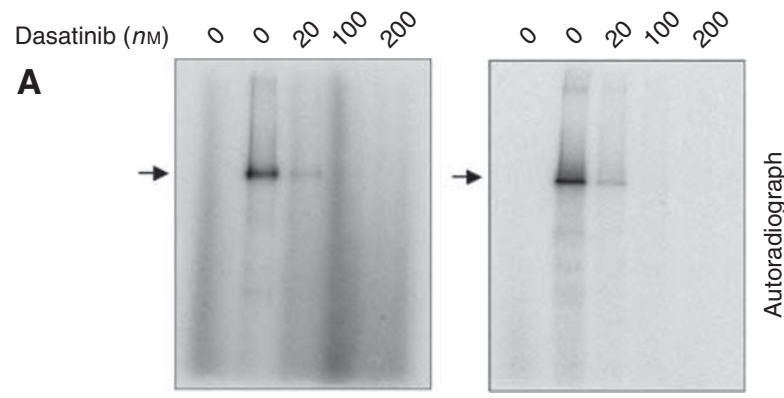

B
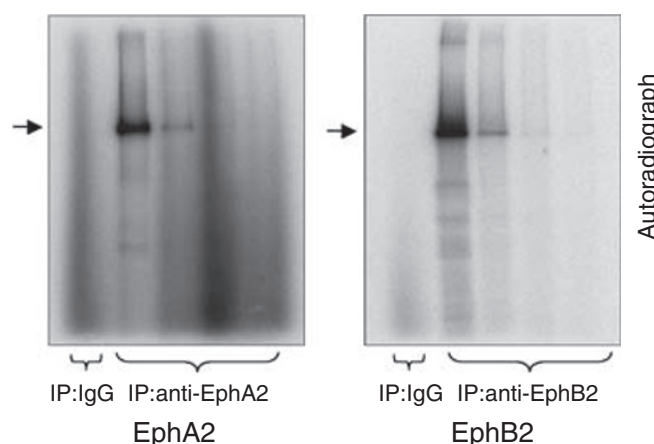

Figure I EphA2 receptor tyrosine kinase activity is inhibited directly by dasatinib. HEK-293 cell lysates transfected with EphA2 or EphB2 constructs were immunoprecipitated with anti-EphA2 or anti-EphB2 antibody and kinase assays were performed in the presence of increasing amounts of dasatinib. Inclusion of dasatinib resulted in decreased autophosphorylation. The same gel was exposed for $5 \mathrm{~h}(\mathbf{A})$ and then exposed for $20 \mathrm{~h}(\mathbf{B})$. 
permeabilised with Triton X-100, treated with ribonuclease, and stained with $50 \mu \mathrm{g} \mathrm{ml}^{-1}$ propidium iodide. DNA histograms were analysed using ModFit LT $^{\mathrm{TM}}$ (Verity, Topsham, ME, USA).

\section{Ligand stimulation, immunoblotting and immunoprecipitation}

Cells in logarithmic growth phase were serum-starved $(0.5 \%$ serum) overnight, stimulated with preclustered $2 \mu \mathrm{g} \mathrm{ml}^{-1}$ ephrin $\mathrm{A} 1-\mathrm{Fc}$ for the indicated times and then processed for immunoblotting and immunoprecipitation. Briefly, cells were washed with icecold PBS and lysed in lysis buffer containing protease inhibitor cocktail tablets (Roche Diagnostics, Laval, Quebec, Canada) for $1 \mathrm{~h}$ on ice. Equivalent amounts of protein (assayed with bicinchoninic acid protein assay from Pierce Biotechnology Inc., Rockford, IL, USA) were separated on $10 \%$ SDS-PAGE gels. Proteins were transferred to polyvinylidene difluoride membranes (Millipore, Bedford, MA, USA) and probed with the appropriate antibodies according to the manufacturer's instructions. For immunoprecipitation, EphA2 or Cbl was immunoprecipitated from $200-500 \mu \mathrm{g}$ cleared lysates using anti-EphA2 or $\mathrm{Cbl}$ antibody plus protein G-Sepharose. Products were fractionated as above and blots probed with anti-phosphotyrosine or anti-EphA2 antibody. Blots were stripped and re-probed with anti-EphA2 or anti-Cbl antibody. Detection was conducted using SuperSignal West
Pico chemiluminescent substrate kits (Pierce Biotechnology Inc., Rockford, IL, USA) or enhanced chemoluminescence Plus detection reagents (GE Healthcare, Piscataway, NJ, USA).

\section{Immunofluorescence microscopy}

Cells were grown on glass chamber slides coated with collagen (125 $\mu \mathrm{g} \mathrm{ml}^{-1}$, BD Biosciences, Mississauga, Ontario, Canada). For staining, cells were fixed with PBS containing $4 \%$ paraformaldehyde for $15 \mathrm{~min}$ at room temperature, permeabilised with $0.2 \%$ Triton X-100, then blocked with PBS containing 10\% FBS. After blocking, cells were incubated with diluted monoclonal antibody overnight at $4{ }^{\circ} \mathrm{C}$ followed by $\mathrm{Cy} 3$-conjugated goat anti-mouse IgG (Jackson ImmunoResearch, West Grove, PA, USA) at room temperature in the dark for $1 \mathrm{~h}$. Control experiments with secondary antibody alone were performed to confirm the absence of background staining. Between each step, cells were washed with PBS. After final washes, slides were coverslipped with Vectashield Mounting Medium with DAPI and examined by confocal microscopy.

\section{BxPC-3 xenografts}

Animal experiments were done in the animal facility of the Princess Margaret Hospital, operated under the guidelines
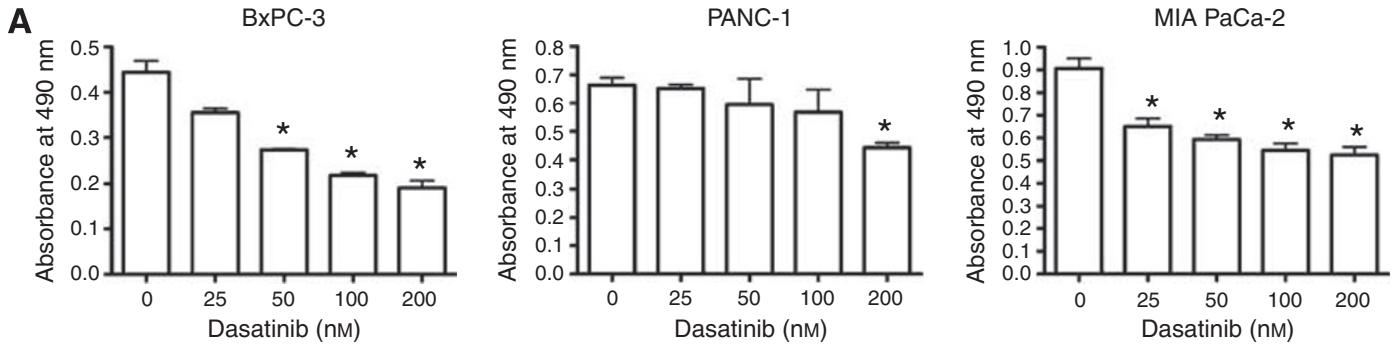

B
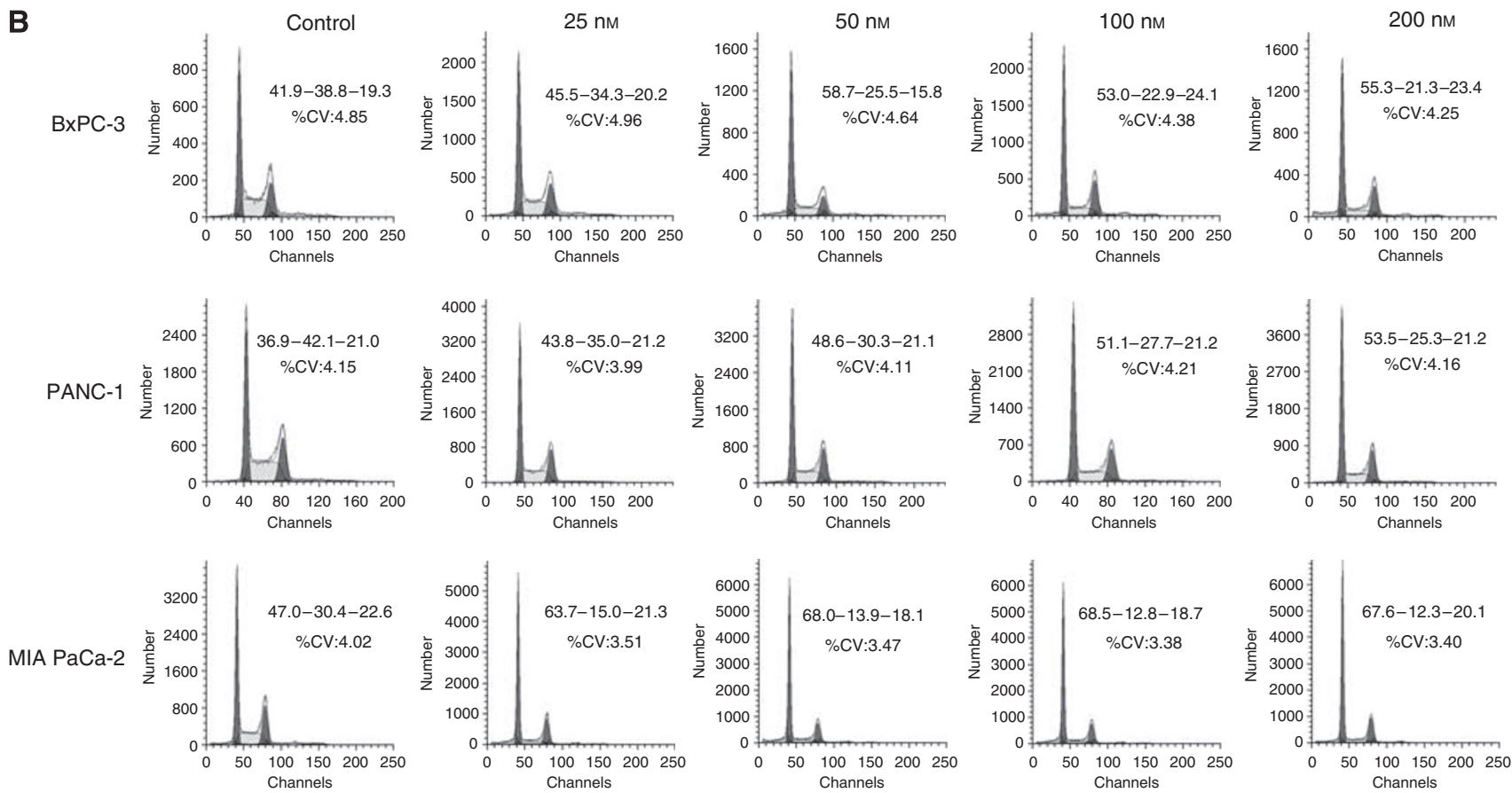

Figure 2 In vitro anti-tumour activity of dasatinib. BxPC-3, PANC-I and MIA PaCa-2 cells were pretreated with 0, 25, 50, I00 and 200 nM dasatinib for 24 or $48 \mathrm{~h}$. (A) Effects of $48 \mathrm{~h}$ treatment with dasatinib on the in vitro growth of BxPC-3, PANC-I and MIA PaCa-2 cells at the indicated concentrations were measured by MTS assay. *Statistically significant from control $(P<0.05)$. (B) Single parameter DNA histograms showed the cell cycle effects of $24 \mathrm{~h}$ treatment with dasatinib at the indicated concentrations. Percent cells in GI-S-G2/M phase are given. CV, coefficient of variation. 
approved by the Canadian Council for Animal Care. BxPC-3 cell suspension ( $\sim 0.5 \mathrm{ml}$; containing approximately $2 \times 10^{6}$ cells) was injected subcutaneously into the left flank of 6-week-old male severe combined immunodeficient mice. After 4 weeks, the tumours became obviously visible. Five groups of three tumourbearing mice were treated with a single dose of dasatinib $\left(50 \mathrm{mg} \mathrm{kg}^{-1}\right)$ or vehicle control ( $80 \mathrm{~mm}$ sodium citrate/citric acid buffer, $\mathrm{pH}$ 3.0) by oral gavage, and killed at 2, 4, 8, and $24 \mathrm{~h}$. Each tumour was rapidly dissected from the surrounding tissues and cut into pieces that were snap frozen in liquid nitrogen, fixed in formalin for $24 \mathrm{~h}$ then paraffin-embedded, or homogenised in $1 \mathrm{ml}$ lysis buffer for western blot and immunoprecipitation.

\section{RESULTS}

EphA2 receptor tyrosine kinase activity is inhibited directly by dasatinib

To determine whether the EphA2 receptor tyrosine kinase activity is inhibited by dasatinib directly or whether the ability of dasatinib to suppress EphA2 activity is an indirect effect of Src inhibition, we performed in vitro autophosphorylation assays. HEK-293 cells expressing EphA2 were immunoprecipitated with anti-EphA2 antibody and kinase assays were performed in the presence of increasing amounts of dasatinib. Reduced autophosphorylation was observed in a dose-dependent manner following addition of dasatinib. Interestingly, dasatinib was also found to inhibit EphB2 directly at similar concentrations (Figure 1).

\section{In vitro anti-tumour activity of dasatinib}

As shown in Figure 2A, there was a dose-dependent decrease in cell numbers following $48 \mathrm{~h}$ treatment with dasatinib in all three cell lines, with MIA PaCa-2 and BxPC-3 showing greater sensitivity than PANC-1. This was associated with a corresponding decrease in the percentages of cells in S phase, as shown in Figure 2B.

\section{EphA2 activation affects downstream signalling}

In all three pancreatic cancer cell lines, low basal levels of EphA2 tyrosine phosphorylation were detected in the absence of ligand, and these showed large increases following ligand stimulation (Figure 3A). As revealed by immunoblotting of total cell lysates with a phosphotyrosine antibody (Figure 3B), the tyrosine phosphorylation of several cellular proteins was significantly induced following ephrinA1-Fc stimulation. We also probed these lysates with phospho-specific antibodies to a number of cellular signalling proteins. BxPC-3 cells showed increased Src phosphorylation at Tyr 416 compared with PANC-1 and MIA PaCa-2 cells and we did not observe obvious responses upon ligand binding in
A

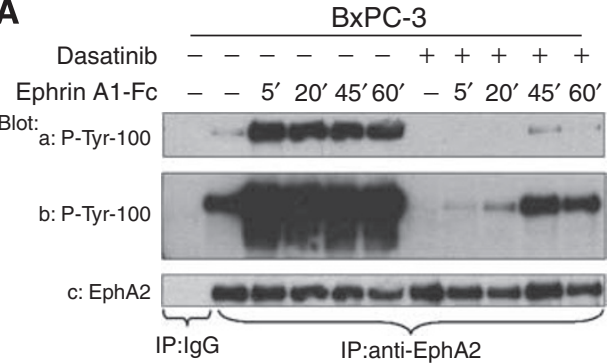

B

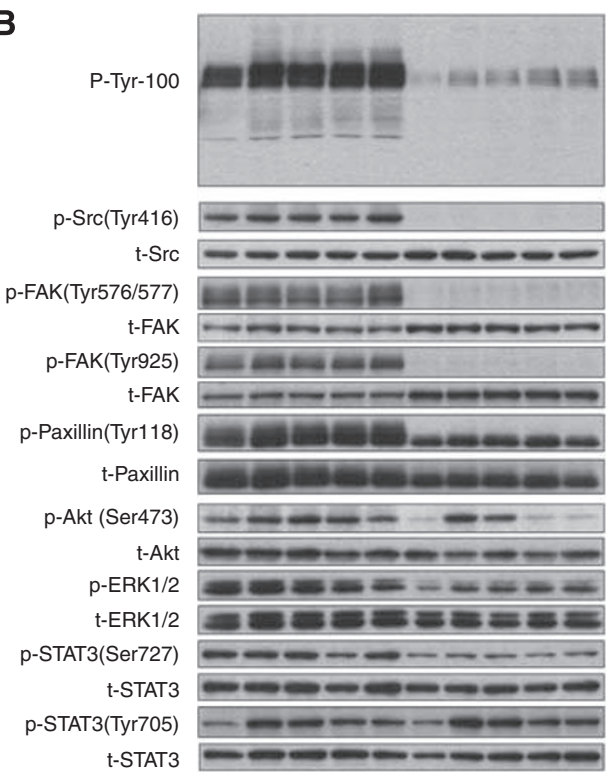

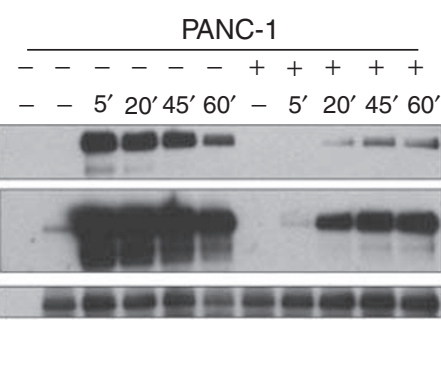
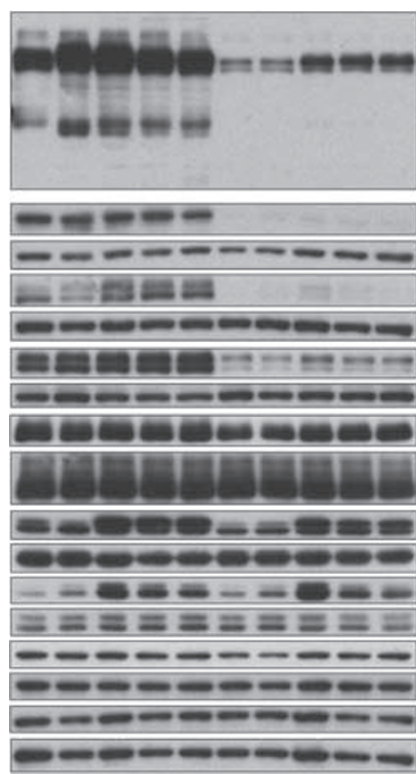
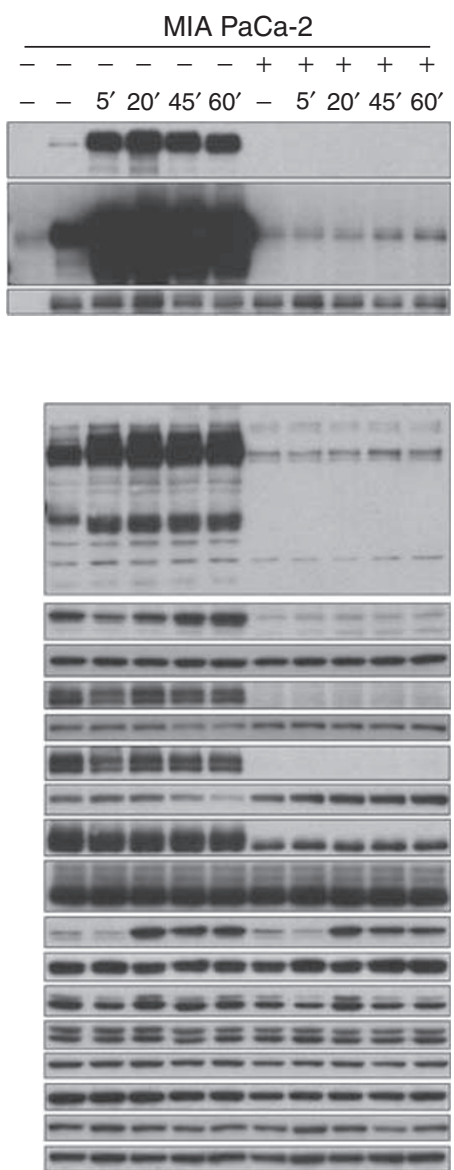

Figure 3 Inhibition of EphA2 receptor tyrosine kinase signalling in pancreatic cancer cell lines. Around 90\% confluent serum-starved BxPC-3, PANC-I and MIA PaCa-2 cells were pretreated with or without $200 \mathrm{nM}$ dasatinib for $2 \mathrm{~h}$ prior to $2 \mu \mathrm{g} \mathrm{ml}{ }^{-1}$ ephrinA I-Fc stimulation for the indicated periods of time. Cells were harvested at various time points. (A) Cell lysates were immunoprecipitated with anti-EphA2 antibody, analysed by phosphotyrosine (P-Tyr-100) and EphA2 immunoblots. The same membrane was exposed for $45 \mathrm{~s}$ (a) and then $10 \mathrm{~min}$ (b) using ECL Plus. EphA2 reprobing (c) served as the loading control. (B) Cell lysates were analysed by western blot using antibodies directed against phosphotyrosine (P-Tyr-100), p-Src (Tyr 416), Src, p-FAK (Tyr 576/577, Tyr 925), FAK, p-Paxillin (Tyr I I8), Paxillin, p-Akt (Ser 473), Akt, p-ERKI/2 (Thr 202/Tyr 204), ERKI/2, p-STAT3 (Ser 727, Tyr 705), STAT3. 
these cells. In contrast, Src and focal adhesion kinase (FAK) showed transient dephosphorylation in PANC-1 and MIA PaCa-2 cells, consistent with previous reports (Miao et al, 2000). However, paxillin, a downstream substrate of FAK, showed no obvious responses to EphA2 activation in any of the three cell lines. Interestingly, our data also showed that Akt phosphorylation at Ser 473 was increased following ligand stimulation. EphA2 activation inhibited p44/42 mitogen-activated protein kinase (MAPK) phosphorylation at Thr 202/Tyr 204 (phosphorylated extracellular signal-regulated kinase, p-ERK1/2) in BxPC-3, yet p-ERK1/2 level was increased at the $20 \mathrm{~min}$ ephrinAl-Fc-binding time point in PANC-1 and MIA PaCa-2. Moreover, we observed that signal transducer and activator of transcription 3 (STAT3) phosphorylation at Tyr 705 was increased upon ligand binding in BxPC-3, but this was much less evident in PANC-1 and MIA PaCa-2 cells. Collectively, stimulation with ligand produced rapid increases of EphA2 phosphorylation, although the effects of EphA2 activation on downstream signalling differed among the pancreatic cancer cell lines. As shown in Supplementary Figure 1, neither ephrinA1 nor EphB2 were detected at significant amounts in any of the three cell lines.

\section{Inhibition of Src by dasatinib}

Consistent with the known effect of dasatinib on Src (Serrels et al, 2006; Shor et al, 2007), Src phosphorylation at Tyr 416 and FAK phosphorylation at the Src-dependent sites (Tyr 576/577, Tyr 925) were dramatically decreased with the pretreatment of dasatinib in all three cell lines as shown in Figure 3B, and this inhibition persisted during $24 \mathrm{~h}$ continuous dasatinib treatment (not shown). Paxillin phosphorylation at Tyr 118 was incompletely inhibited by dasatinib. As shown in Figure 4, Src, FAK and Paxillin phosphorylations were inhibited by dasatinib in a dose-dependent manner, with or without ephrinAl-Fc ligand stimulation, and similar effects were seen with the well-characterised Src inhibitor PP2.

\section{Inhibition of EphA2 by dasatinib}

Pretreatment with dasatinib inhibited the low levels of constitutive EphA2 tyrosine phosphorylation, as well as ligand-induced activation in all three cell lines (Figure 3A). Inhibition of EphA2 tyrosine phosphorylation was dose-dependent and the $\mathrm{IC}_{50}$ was similar to that for $\mathrm{p}$-Src. In contrast, PP2 exhibited minimal inhibition of EphA2 tyrosine phosphorylation in BxPC-3 cells except at the highest concentration tested $(20 \mu \mathrm{M})$ (Figure 4$)$.

\section{Effects of dasatinib on ephrinA1-Fc stimulation}

We next examined the effects of dasatinib on the activation of downstream signalling in response to ephrinA1-Fc stimulation. In the absence of ligand, treatment with dasatinib partially inhibited Akt phosphorylation at Ser 473, ERK phosphorylation at Thr 202/Tyr 204, and STAT3 phosphorylation at Ser 727 but not Tyr 705 in all three cell lines (Figure 3B). Unexpectedly, pretreatment with dasatinib at concentrations that strongly inhibited EphA2 tyrosine phosphorylation failed to suppress completely ligand-induced activation of Akt and ERK1/2 in all three cell lines, and also the activation of STAT3 Tyr 705 that occurred in BxPC-3 cells.

\section{Dasatinib inhibits ligand-induced EphA2 internalisation and degradation}

Previous work has shown that ligand-binding results in the internalisation and proteasomal degradation of EphA2, which is Cbl-dependent (Walker-Daniels et al, 2002; Wang et al, 2002).
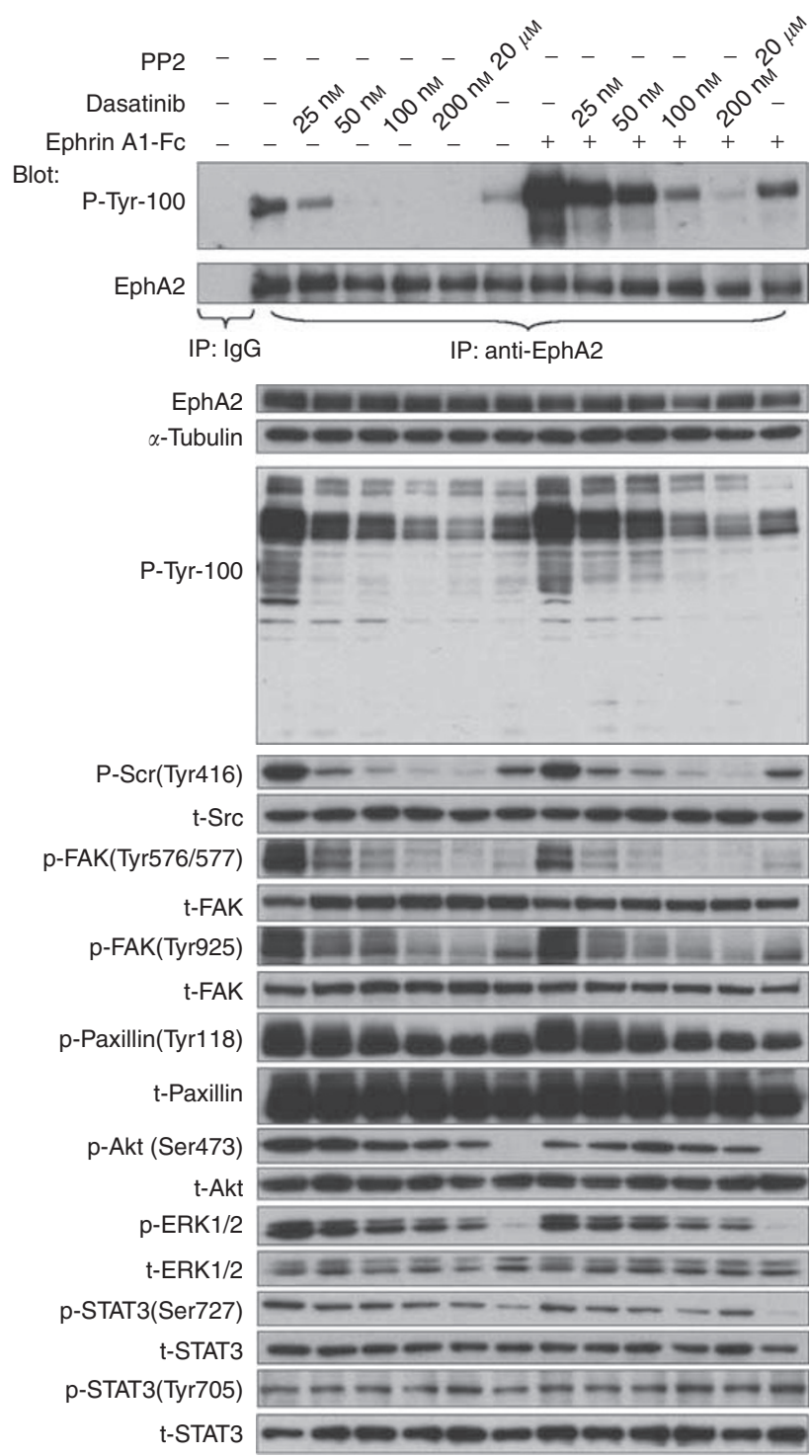

Figure 4 Inhibition of EphA2 receptor tyrosine kinase is dosedependent. Around $90 \%$ confluent serum-starved BxPC-3 cells were pretreated with the indicated concentration of dasatinib or $20 \mu \mathrm{M}$ PP2 for $2 \mathrm{~h}$ prior to $2 \mu \mathrm{g} \mathrm{ml}^{-1}$ ephrinAl-Fc stimulation for $5 \mathrm{~min}$. Cell lysates were immunoprecipitated with anti-EphA2 antibody, analysed by phosphotyrosine (P-Tyr-100) and EphA2 immunoblots. The cell lysates were also analysed by western blot using the indicated antibodies.

Subconfluent BxPC-3, PANC-1 and MIA PaCa-2 cells were pretreated with solvent or $200 \mathrm{nM}$ dasatinib for $2 \mathrm{~h}$, then stimulated with $2 \mu \mathrm{g} \mathrm{ml}^{-1}$ ephrinA1-Fc for $30 \mathrm{~min}$. In the absence of dasatinib, a large increase in EphA2 association with $\mathrm{Cbl}$ was observed upon ligand stimulation, concordant with the increased level of EphA2 autophosphorylation. As shown in Figure 5A, this effect was strongly inhibited by dasatinib in all three cell lines. We also observed that although there was a pronounced decrease in the total protein levels of EphA2 $3 \mathrm{~h}$ following ligand stimulation, consistent proteasomal degradation of the receptor, this effect was diminished in the presence of dasatinib (Figure 5B). Furthermore, using confocal microscopy, we observed that the subcellular distribution of EphA2 showed internalisation followed by degradation after exposure to ephrinA1-Fc, whereas the cell surface distribution of EphA2 was maintained with dasatinib pretreatment (Figure 5C). 
A

Dasatinib

Ephrin A1-Fc

Blot:

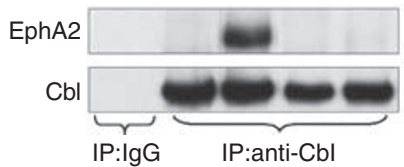

Blot:

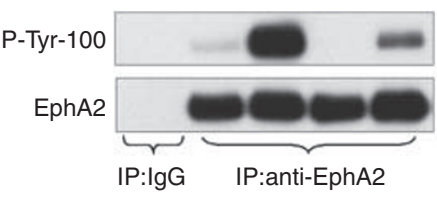

Blot:

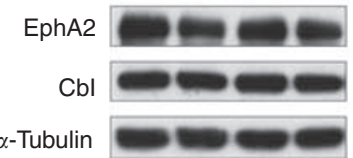

B

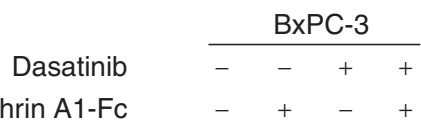

Blot: EphA2

Fold change $\rightarrow \begin{array}{llll}1 & 0.14 & 0.62 & 0.79\end{array}$

$\alpha$-Tubulin

C
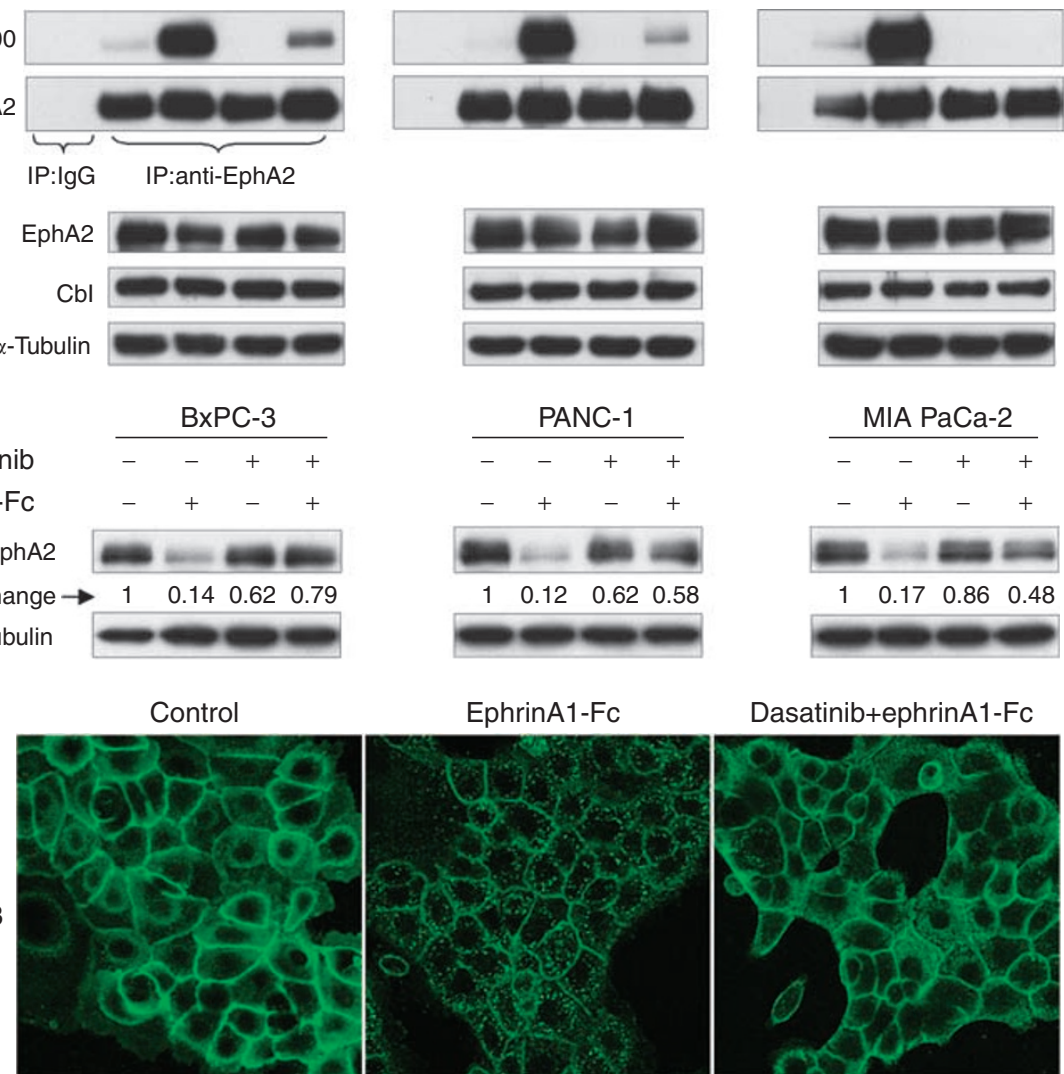

EphrinA1-Fc

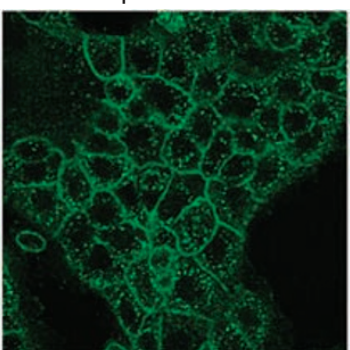

Dasatinib+ephrinA1-Fc

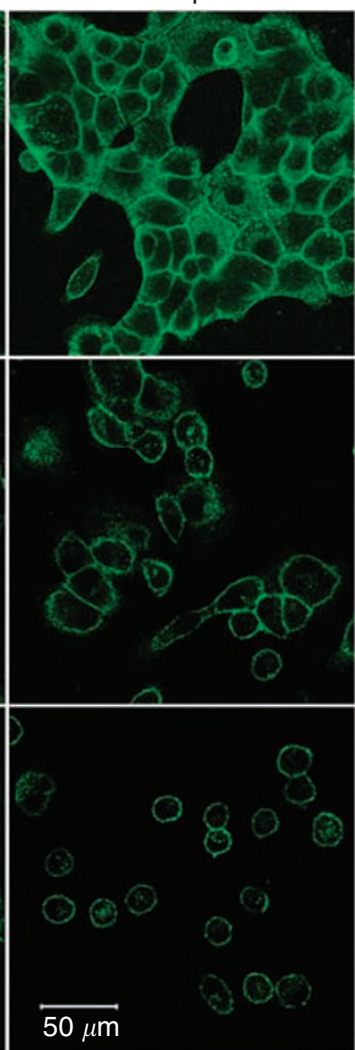

Figure 5 Dasatinib inhibits ligand-induced EphA2 internalisation and degradation. Approximately $90 \%$ confluent BxPC-3, PANC-I and MIA PaCa-2 cells were pretreated with $200 \mathrm{nM}$ dasatinib for $2 \mathrm{~h}$ prior to $2 \mu \mathrm{g} \mathrm{ml}{ }^{-1}$ ephrinAl-Fc stimulation. (A) Cell lysates were immunoprecipitated with anti-Cbl or antiEphA2 antibody 30 min following ligand stimulation, and analysed by EphA2, phosphotyrosine (P-Tyr-100) or Cbl immunoblots. Cell lysates were also analysed by western blot using anti-EphA2 or anti-Cbl antibody. $\alpha$-Tubulin served as the loading control. (B) Cell lysates probed for EphA2 $3 \mathrm{~h}$ following ligand activation. Densitometric data (fold change) are shown, normalised to $\alpha$-tubulin. (C) The subcellular distribution of EphA2 30 min following ligand activation was evaluated using confocal microscopy. Contrast enhancement was applied uniformly to all panels. 


\section{Inhibition of EphA2 receptor tyrosine kinase signalling in} BxPC-3 xenografts

BxPC-3 cells are the most responsive to dasatinib in vitro among three pancreatic cell lines, and therefore selected for the in vivo experiments. BxPC-3 tumour-bearing mice were treated with a single dose of $50 \mathrm{mg} \mathrm{kg}^{-1}$ dasatinib and killed at various time points. As shown in Figure 6, EphA2 tyrosine phosphorylation was readily detectable in the xenografts. This was partially inhibited after 2 and $4 \mathrm{~h}$ of dasatinib administration, similar to our results in vitro, but at the $8 \mathrm{~h}$ time point EphA2 phosphorylation was increased above the baseline. Phosphotyrosine proteins were decreased following dasatinib administration, but not to the extent seen in the in vitro studies. Src and FAK dephosphorylation occurred after 2 and $4 \mathrm{~h}$ of dasatinib administration as expected, and phosphorylation gradually recovered to pretreatment at $24 \mathrm{~h}$, consistent with the pharmacokinetics of this compound (Lombardo et al, 2004). These results show that in addition to Src, EphA2 autophosphorylation is inhibited by dasatinib in vivo.

\section{DISCUSSION}

Our study focused on the inhibition of EphA2 receptor tyrosine kinase activity by dasatinib in pancreatic cancer. Although

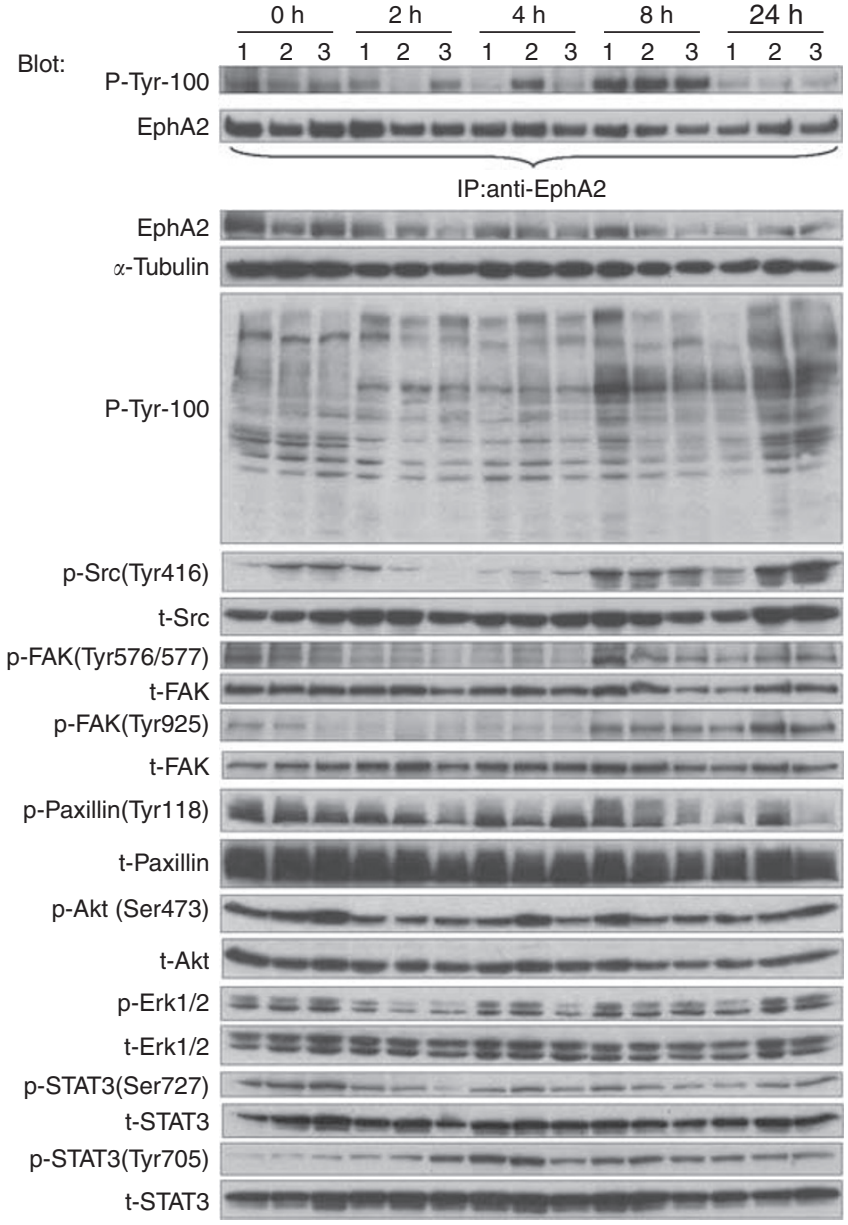

Figure 6 Inhibition of EphA2 receptor tyrosine kinase signalling in BxPC 3 xenografts. Mice bearing BxPC-3 xenografts were treated with single dose of $50 \mathrm{mg} \mathrm{kg}^{-1}$ dasatinib or vehicle control for the indicated periods of time. The zero time points are drug vehicle controls. Tumour lysates were immunoprecipitated with anti-EphA2 antibody, analysed by phosphotyrosine (P-Tyr-100) and EphA2 immunoblots. The tumour lysates were also analysed by western blot using the indicated antibodies. previous studies have demonstrated that dasatinib suppresses cell adhesion, migration, and invasion, and has potential as a therapeutic agent for metastatic cancers through Src inhibition (Johnson et al, 2005; Trevino et al, 2006; Shor et al, 2007), it seems that not all of its biological and molecular effects are due to Src inhibition (Johnson et al, 2005). As Src has been suggested to be involved in the activation of Eph receptors (Knöll and Drescher, 2004; Landen et al, 2006), we tested for direct inhibitory effect of dasatinib on Eph receptors using an in vitro kinase assay. The results show that dasatinib inhibits EphA2 directly, which is consistent with a recent study which reported that dasatinib has an $\mathrm{IC}_{50}$ of $17 \mathrm{nmoll}^{-1}$ for EphA2 (Huang et al, 2007). Interestingly, dasatinib was also found to inhibit EphB2 directly at similar concentrations, suggesting that this agent is a more general Eph receptor inhibitor as has been suggested recently by others (Bantscheff et al, 2007; Rix et al, 2007). This is potentially important as distinct biological effects have been reported for the different Eph receptors. For example, EphB2 activity is believed to have a function in suppressing tumour progression and metastasis (Huusko et al, 2004; Batlle et al, 2005).

In this report, we detected low basal levels of EphA2 tyrosine phosphorylation in BxPC-3, PANC-1 and MIA PaCa-2 pancreatic cancer cell lines, and these were further enhanced following ligand stimulation. But the influence of Eph/ephrin activation on cell behaviour differs depending on the cell type (Kullander and Klein, 2002). Src and FAK showed transient dephosphorylation following ligand stimulation in PANC-1 and MIA PaCa-2 cells but not in BxPC-3 cells, consistent with previous studies (Miao et al, 2000; Duxbury et al, 2004), indicating that EphA2 is constitutively associated with Src and FAK, and may have an important function in regulating their functions. In contrast, paxillin, a downstream substrate of FAK, showed no obvious responses to EphA2 activation in all three cell lines.

Although Src can activate Akt directly (Jiang and Qiu, 2003) and as well affect Ras-MAPK pathway (Olayioye et al, 2001), activation of the EphA2 kinase has been shown to stimulate the MAPK pathway (Pratt and Kinch, 2002) and phosphoinositide 3 kinase pathway (Pandey et al, 1994). In contrast, others have shown that activated EphA2 downregulates the Ras-MAPK pathway (Miao et al, 2001). A recent study has demonstrated that EphA2 is a direct transcriptional target of the Ras-Raf-MAPK pathway, and ligandstimulated EphA2 attenuates the growth factor-induced activation of this pathway. EphA2 signalling contributes to a feedback loop that regulates Ras activity in a ligand-dependent manner (Macrae et al, 2005). Our results show activation of EphA2 kinase stimulates Akt in all three cell lines. Furthermore, EphA2 activation inhibits ERK phosphorylation in BxPC-3 cells, whereas producing increased ERK phosphorylation in PANC-1 and MIA PaCa-2 cells. The explanation for this is not clear, although it should be noted that BxPC-3 cells possess a wild-type K-Ras, whereas this is mutant in PANC-1 and MIA PaCa-2.

STAT3 is a key signalling molecule for many cytokines and growth factor receptors. Transcriptional activation seems to be regulated by phosphorylation at Ser 727 through the MAPK or mammalian target of rapamycin (mTOR) pathway (Yokogami et al, 2000; Kanai et al, 2003). Although activation of STAT3 is linked to persistent activity of tyrosine kinases, including Src (Yeatman, 2004), STAT3 phosphorylation at Tyr 705, in response to cytokine stimulation, is generally mediated by Janus-activated kinase 1 (Ihle, 1995). Interestingly, we found that in BxPC-3 cells, STAT3 phosphorylation at Ser 727 was inhibited by dasatinib but unresponsive to ligand stimulation, whereas Tyr 705 was increased following ephrinA1-Fc-binding and this effect was not inhibited by dasatinib. As reported previously (Johnson et al, 2005, 2007), the activation of STAT3 may be a compensatory effect that suppresses the pro-apoptotic or anti-proliferative effects of dasatinib.

Dasatinib strongly inhibited EphA2 tyrosine phosphorylation of EphA2 at dose levels similar to those that inhibited Src in all three 
cell lines. However, as seen in Figure 2C, pronounced increases in Akt and ERK activation occurred following ligand-induced stimulation in the presence of dasatinib, whereas this was inhibited by LY294002 and U0126, respectively, as expected (data not shown). This contrasts with an extensive literature documenting that small molecule inhibitors of other RTKs such as epidermal growth factor receptor strongly inhibit ligand-induced activation of ERK and Akt. The explanation for this effect is not clear. Possibly sufficient activation of EphA2 (or perhaps a different ephrinA1-responsive receptor) persists to affect downstream signalling in the presence of dasatinib. Alternatively, higher-order clustering through the STERILE $\alpha$-MOTIF (SAM) domain or the $\mathrm{PDZ}$ recognition motif might regulate ligand-stimulated signalling events (Kullander and Klein, 2002) independent of tyrosine kinase activity, and therefore insensitive to dasatinib.

Cell-cell contacts promote ligand binding, and ligand binding induces so-called 'forward signalling' mostly through phosphotyrosine-mediated pathways (Kullander and Klein, 2002). Upon ligand stimulation, EphA2 aggregates at the cell surface and becomes tyrosine-phosphorylated, which promotes the formation of a protein complex with the c-Cbl adapter protein (Walker-Daniels et al, 2002). The complex of EphA2 and Cbl is then internalised into early endosomes, where EphA2 is subsequently degraded through proteosomal and lysosomal pathways. Exposure to ligand mimetics (ephrin $\mathrm{A} 1-\mathrm{Fc}$ ) has been shown trigger rapid EphA2 phosphorylation and receptor downregulation in MDA-MB-231 breast (Zantek et al, 1999; Kiewlich et al, 2006) and PC-3 prostate (Miao et al, 2000) cancer cells. We observed that dasatinib inhibited ligand-induced $\mathrm{Cbl}$ binding and the internalisation and degradation of EphA2, suggesting that these are dependent on kinase activity as has also been shown for kinasedead Eph receptors (Zimmer et al, 2003). We suggest that through the inhibition of ligand-induced EphA2 degradation, dasatinib might act to stabilise receptor/ligand binding, thereby promoting adhesive rather than repulsive interactions, and suppressing tumour invasiveness.

Preliminary experiments showed that treatment with dasatinib results in a transient decrease of EphA2 phosphorylation in BxPC3 xenografts, indicating that this compound can modulate EphA2 at doses that are achievable in vivo. Dasatinib might therefore have activity in pancreatic cancer because of EphA2 inhibition, in addition to its effects on Src.

EphA2 is overexpressed in a number of human cancers, including pancreatic cancer, and this is associated with poor prognosis. Various strategies have been proposed to target EphA2 in cancer, including the use of monoclonal antibodies directed at EphA2 surface antigens and RNAi to EphA2 (Carles-Kinch et al, 2002; Landen et al, 2005). Although it remains unclear if the activation of EphA2 tyrosine kinase is necessary for its role in cancer progression, our results suggest that more selective small molecule inhibitors of EphA2 might also have clinical value.

\section{ACKNOWLEDGEMENTS}

We thank May Cheung, Pinjiang Cao, Andrew Morrison, James $\mathrm{Ho}$, Jing $\mathrm{Xu}$ for their excellent technical assistance, and Danni Li, Joao Magalhaes, Joerg Schwock, Nhu-An Pham for their support of this research. The work was supported by the National Cancer Institute of Canada using funds raised by the Canadian Cancer Society.

Supplementary Information accompanies the paper on British Journal of Cancer website (http://www.nature.com/bjc)

\section{REFERENCES}

Bantscheff M, Eberhard D, Abraham Y, Bastuck S, Boesche M, Hobson S, Mathieson T, Perrin J, Raida M, Rau C, Reader V, Sweetman G, Bauer A, Bouwmeester T, Hopf C, Kruse U, Neubauer G, Ramsden N, Rick J, Kuster B, Drewes G (2007) Quantitative chemical proteomics reveals mechanisms of action of clinical ABL kinase inhibitors. Nat Biotechnol 25: $1035-1044$

Batlle E, Bacani J, Begthel H, Jonkeer S, Gregorieff A, Born Mvd, Malats Nr, Sancho E, Boon E, Pawson T, Gallinger S, Pals S, Clevers H (2005) EphB receptor activity suppresses colorectal cancer progression. Nature 435: $1126-1130$

Brantley DM, Cheng N, Thompson EJ, Lin Q, Brekken RA, Thorpe PE, Muraoka RS, Cerretti DP, Pozzi A, Jackson D, Lin C, Chen J (2002) Soluble Eph A receptors inhibit tumor angiogenesis and progression in vivo. Oncogene 21: $7011-7026$

Carles-Kinch K, Kilpatrick KE, Stewart JC, Kinch MS (2002) Antibody targeting of the EphA2 tyrosine kinase inhibits malignant cell behavior. Cancer Res 62: $2840-2847$

Dobrzanski P, Hunter K, Jones-Bolin S, Chang H, Robinson C, Pritchard S, Zhao H, Ruggeri B (2004) Antiangiogenic and antitumor efficacy of EphA2 receptor antagonist. Cancer Res 64: 910 -919

Dodelet VC, Pasquale EB (2000) Eph receptors and ephrin ligands: embryogenesis to tumorigenesis. Oncogene 19: 5614-5619

Duxbury MS, Ito H, Zinner MJ, Ashley SW, Whang EE (2004) Ligation of EphA2 by Ephrin A1-Fc inhibits pancreatic adenocarcinoma cellular invasiveness. Biochem Biophys Res Commun 320: $1096-1102$

Easty DJ, Herlyn M, Bennett DC (1995) Abnormal protein tyrosine kinase gene expression during melanoma progression and metastasis. Int $J$ Cancer 60: $129-136$

Fang WB, Brantley-Sieders DM, Parker MA, Reith AD, Chen J (2005) A kinase-dependent role for EphA2 receptor in promoting tumor growth and metastasis. Oncogene 24: 7859-7868

Guo H, Miao H, Gerber L, Singh J, Denning MF, Gilliam AC, Wang B (2006) Disruption of EphA2 receptor tyrosine kinase leads to increased susceptibility to carcinogenesis in mouse skin. Cancer Res 66: $7050-7058$

Holland SJ, Gale NW, Gish GD, Roth RA, Zhou S, Cantley LC, Henkemeyer M, Yancopoulos GD, Pawson T (1997) Juxtamembrane tyrosine residues couple the Eph family receptor EphB2/Nuk to specific SH2 domain proteins in neuronal cells. EMBO J 16: $3877-3888$

Huang F, Reeves K, Han X, Fairchild C, Platero S, Wong TW, Lee F, Shaw P, Clark E (2007) Identification of candidate molecular markers predicting sensitivity in solid tumors to dasatinib: rationale for patient selection. Cancer Res 67: 2226-2238

Huusko P, Ponciano-Jackson D, Wolf M, Kiefer JA, Azorsa DO, Tuzmen S, Weaver D, Robbins C, Moses T, Allinen M, Hautaniemi S, Chen Y, Elkahloun A, Basik M, Bova GS, Bubendorf L, Lugli A, Sauter G, Schleutker J, Ozcelik H, Elowe S, Pawson T, Trent JM, Carpten JD, Kallioniemi OP, Mousses S (2004) Nonsense-mediated decay microarray analysis identifies mutations of EPHB2 in human prostate cancer. Nat Genet 36: $979-983$

Ihle JN (1995) Cytokine receptor signalling. Nature 377: $591-594$

Ireton RC, Chen J (2005) EphA2 receptor tyrosine kinase as a promising target for cancer therapeutics. Curr Cancer Drug Targets 5: 149-157

Jiang T, Qiu Y (2003) Interaction between Src and a C-terminal prolinerich motif of Akt is required for Akt activation. J Biol Chem 278: $15789-15793$

Johnson F, Saigal B, Tran H, Donato N (2007) Abrogation of signal transducer and activator of transcription 3 reactivation after Src kinase inhibition results in synergistic antitumor effects. Clin Cancer Res 13: $4233-4244$

Johnson FM, Saigal B, Talpaz M, Donato NJ (2005) Dasatinib (BMS-354825) tyrosine kinase inhibitor suppresses invasion and induces cell cycle arrest and apoptosis of head and neck squamous cell carcinoma and non-small cell lung cancer cells. Clin Cancer Res 11: 6924-6932

Kanai M, Konda Y, Nakajima T, Izumi Y, Kanda N, Nanakin A, Kubohara Y, Chiba T (2003) Differentiation-inducing factor-1 (DIF-1) inhibits 
STAT3 activity involved in gastric cancer cell proliferation via MEKERK-dependent pathway. Oncogene 22: 548-554

Kiewlich D, Zhang J, Grossy C, Xiay W, Larseny B, Cobby RR, Birocy S, Guy J-M, Satoy T, Lighty DR, Heitnery T, Willudaz J, Vogely D, Monteclaroy F, Citkowiczy A, Roffler SR, Zajchowski DA (2006) AntiEphA2 antibodies decrease EphA2 protein levels in murine CT26 colorectal and human MDA-231 breast tumors but do not inhibit tumor growth. Neoplasia 8: $18-30$

Kinch MS, Burridge K (1995) Altered adhesions in ras-transformed breast epithelial cells. Biochem Soc Trans 23: 446-450

Kinch MS, Carles-Kinch K (2003) Overexpression and functional alterations of the EphA2 tyrosine kinase in cancer. Clin Exp Metastasis 20: $59-68$

Kinch MS, Moore M-B, Harpole Jr DH (2003) Predictive value of the EphA2 receptor tyrosine kinase in lung cancer recurrence and survival. Clin Cancer Res 9: 613-618

Knöll B, Drescher U (2004) Src family kinases are involved in EphA receptor-mediated retinal axon guidance. J Neurosci 24: 6248-6257

Kullander K, Klein R (2002) Mechanisms and functions of Eph and ephrin signalling. Nat Rev Mol Cell Biol 3: 475-486

Landen Jr CN, Chavez-Reyes A, Bucana C, Schmandt R, Deavers MT, Lopez-Berestein G, Sood AK (2005) Therapeutic EphA2 gene targeting in vivo using neutral liposomal small interfering RNA delivery. Cancer Res 65: 6910-6918

Landen Jr CN, Lu C, Han LY, Coffman KT, Bruckheimer E, Halder J, Mangala LS, Merritt WM, Lin YG, Gao C, Schmandt R, Kamat AA, Li Y, Thaker P, Gershenson DM, Parikh NU, Gallick GE, Kinch MS, Sood AK (2006) Efficacy and antivascular effects of EphA2 reduction with an agonistic antibody in ovarian cancer. J Natl Cancer Inst 98: 1558-1570

Lombardo LJ, Lee FY, Chen P, Norris D, Barrish JC, Behnia K, Castaneda S, Cornelius LA, Das J, Doweyko AM, Fairchild C, Hunt JT, Inigo I, Johnston K, Kamath A, Kan D, Klei H, Marathe P, Pang S, Peterson R, Pitt S, Schieven GL, Schmidt RJ, Tokarski J, Wen M-L, Wityak J, Borzilleri RM (2004) Discovery of N-(2-chloro-6-methyl- phenyl)-2 (6-(4-(2-hydroxyethyl)- piperazin-1-yl)-2-methylpyrimidin-4- ylamino) thiazole-5-carboxamide (BMS-354825), a dual Src/Abl kinase inhibitor with potent antitumor activity in preclinical assays. J Med Chem 47: $6658-6661$

Macrae M, Neve RM, Rodriguez-Viciana P, Haqq C, Yeh J, Chen C, Gray JW, McCormick F (2005) A conditional feedback loop regulates Ras activity through EphA2. Cancer cell 8: 111-118

Miao H, Burnett E, Kinch M, Simon E, Wang B (2000) Activation of EphA2 kinase suppresses integrin function and causes focal-adhesion kinase dephosphorylation. Nat Cell Biol 2: 62-69

Miao H, Wei B-R, Peehl DM, Li Q, Alexandrou T, Schelling JR, Rhim JS, Sedor JR, Burnett E, Wang B (2001) Activation of EphA receptor tyrosine kinase inhibits the Ras/MAPK pathway. Nat Cell Biol 3: 527-530

Miyazaki T, Kato H, Fukuchi M, Nakajima M, Kuwano H (2003) EphA2 overexpression correlates with poor prognosis in esophageal squamous cell carcinoma. Int J Cancer 103: 657-663

Mudali SV, Fu B, Lakkur SS, Luo M, Embuscado EE, Iacobuzio-Donahue CA (2006) Patterns of EphA2 protein expression in primary and metastatic pancreatic carcinoma and correlation with genetic status. Clin Exp Metastasis 23: 357-365

Nakamoto M, Bergemann AD (2002) Diverse roles for the Eph family of receptor tyrosine kinases in carcinogenesis. Microsc Res Tech 59: 58-67

Ogawa K, Pasqualini R, Lindberg RA, Kain R, Freeman AL, Pasquale EB (2000) The ephrin-A1 ligand and its receptor, EphA2, are expressed during tumor neovascularization. Oncogene 19: 6043-6052

Olayioye MA, Badache A, Daly JM, Hynes NE (2001) An essential role for Src kinase in ErbB receptor signaling through the MAPK pathway. Exp Cell Res 267: $81-87$
Pandey A, Lazar DF, Saltiel AR, Dixit VM (1994) Activation of the Eck receptor protein tyrosine kinase stimulates phosphatidylinositol 3-kinase activity. J Biol Chem 269: 30154-30157

Pasquale EB (2004) Eph-ephrin promiscuity is now crystal clear. Nat Neurosci 7: $417-418$

Pratt RL, Kinch MS (2002) Activation of the EphA2 tyrosine kinase stimulates the MAP/ERK kinase signaling cascade. Oncogene 21: $7690-7699$

Rix U, Hantschel O, Durnberger G, Remsing Rix LL, Planyavsky M, Fernbach NV, Kaupe I, Bennett KL, Valent P, Colinge J, Kocher T, Superti-Furga G (2007) Chemical proteomic profiles of the BCR-ABL inhibitors imatinib, nilotinib, and dasatinib reveal novel kinase and nonkinase targets. Blood 110: 4055-4063

Serrels A, Macpherson IR, Evans TR, Lee FY, Clark EA, Sansom OJ, Ashton GH, Frame MC, Brunton VG (2006) Identification of potential biomarkers for measuring inhibition of Src kinase activity in colon cancer cells following treatment with dasatinib. Mol Cancer Ther 5: $3014-3022$

Shor AC, Keschman EA, Lee FY, Muro-Cacho C, Letson GD, Trent JC, Pledger WJ, Jove R (2007) Dasatinib inhibits migration and invasion in diverse human sarcoma cell lines and induces apoptosis in bone sarcoma cells dependent on SRC kinase for survival. Cancer Res 67: 2800-2808

Talpaz M, Shah NP, Kantarjian H, Donato N, Nicoll J, Paquette R, Cortes J, O’Brien S, Nicaise C, Bleickardt E, Blackwood-Chirchir MA, Iyer V, Chen T-T, Huang F, Decillis AP, Sawyers CL (2006) Dasatinib in imatinibresistant Philadelphia chromosome-positive leukemias. $N$ Engl J Med 354: $2531-2541$

Trevino JG, Summy JM, Lesslie DP, Parikh NU, Hong DS, Lee FY, Donato NJ, Abbruzzese JL, Baker CH, Gallick GE (2006) Inhibition of SRC expression and activity inhibits tumor progression and metastasis of human pancreatic adenocarcinoma cells in an orthotopic nude mouse model. Am J Pathol 168: $962-972$

Walker-Daniels J, Hess AR, Hendrix MJ, Kinch MS (2003) Differential regulation of EphA2 in normal and malignant cells. Am J Pathol 162: $1037-1042$

Walker-Daniels J, Riese II DJ, Kinch MS (2002) c-Cbl-dependent EphA2 protein degradation is induced by ligand binding. Mol Cancer Res 1: $79-87$

Wang XD, Reeves K, Luo FR, Xu LA, Lee F, Clark E, Huang F (2007) Identification of candidate predictive and surrogate molecular markers for dasatinib in prostate cancer: rationale for patient selection and efficacy monitoring. Genome Biol 8: R255

Wang Y, Ota S, Kataoka H, Kanamori M, Li Z, Band H, Tanaka M, Sugimura H (2002) Negative regulation of EphA2 receptor by $\mathrm{Cbl}$. Biochem Biophys Res Commun 296: 214-220

Yeatman TJ (2004) A renaissance for SRC. Nat Rev Cancer 4: 470 - 480

Yokogami K, Wakisaka S, Avruch J, Reeves SA (2000) Serine phosphorylation and maximal activation of STAT3 during CNTF signaling is mediated by the rapamycin target mTOR. Curr Biol 10: 47-50

Zantek ND, Azimi M, Fedor-Chaiken M, Wang B, Brackenbury R, Kinch MS (1999) E-cadherin regulates the function of the EphA2 receptor tyrosine kinase. Cell Growth Differ 10: 629-638

Zantek ND, Walker-Daniels J, Stewart J, Hansen RK, Robinson D, Miao H, Wang B, Kung H-J, Bissell MJ, Kinch MS (2001) MCF-10A-NeoST: a new cell system for studying cell-ECM and cell-cell interactions in breast cancer. Clin Cancer Res 7: 3640-3648

Zelinski DP, Zantek ND, Stewart JC, Irizarry AR, Kinch MS (2001) EphA2 overexpression causes tumorigenesis of mammary epithelial cells. Cancer Res 61: 2301-2306

Zimmer M, Palmer A, Kohler J, Klein R (2003) EphB-ephrinB bi-directional endocytosis terminates adhesion allowing contact mediated repulsion. Nat Cell Biol 5: 869-878 